\title{
Effect of over-ply on moisture absorption behavior of scarf-repaired composite laminate
}

\author{
Jie Zhang a,b, Xiaoquan Cheng ${ }^{\mathrm{a}, *}$, Yujia Cheng ${ }^{\mathrm{a}}, \mathrm{Xin}_{\mathrm{Guo}}^{\mathrm{a}}$, Liu Yang ${ }^{\mathrm{c}}$ \\ ${ }^{a}$ School of Aeronautic Science and Engineering, Beihang University, Beijing, 100083, China \\ ${ }^{\mathrm{b}}$ Institute of telecommunication satellite, China academy of spacecraft technology, Beijing, \\ 100094, China \\ ${ }^{c}$ Department of Mechanical and Aerospace Engineering, University of Strathclyde, 75 Montrose \\ Street, Glasgow, G1 1XJ, United Kingdom
}

Abstract: The over-ply covering the bondline in scarf-repaired laminates can avoid direct exposure of the adhesive to moisture environment which would decrease the properties of the adhesive. The effect of the over-ply on moisture absorption behavior of scarf-repaired composite laminate was studied in this paper. 3D finite element models (FEMs) of scarf-repaired laminates with and without over-ply were established to simulate the moisture absorption behavior and verified by experimental results. Then these models were used to investigate the effects of some factors, including over-ply type, configuration, direction and number, on moisture absorption behavior of the repaired structures, especially of the adhesive. The results show that the over-ply can efficiently decelerate moisture absorption of the adhesive and delay the time of its moisture absorption equilibrium. Over-ply type has effect on moisture absorption of the adhesive. Woven over-ply is more effective to protect the adhesive in repaired laminates from moisture absorption than unidirectional over-ply. For the laminates with only large-circle bonding surface covered, over-ply lap length, configuration and direction are not very important parameters to affect the moisture

\footnotetext{
* Corresponding author. Tel.: +86 13810390249.
}

E-mail address: xiaoquan_cheng@buaa.edu.cn. 
absorption.

Keywords: composite laminate, scarf repair, over-ply, moisture absorption behavior 


\section{Introduction}

Composite materials have widely applied in many fields because of the superior mechanical performances over metal materials. The damage in composite structures may occur during the service life due to several causes, such as complicated loading conditions, foreign object impacts and so on [1]. Local repair of damaged composite structures is significant for structural integrity and economic benefits $[2,3]$. Compared with other repair methods, scarf repair can efficiently keep the aerodynamic shape of surface structures, thus it is widely applied in aeronautical field and other fields $[4,5]$.

Composite structures in aircrafts may suffer high-moisture environment during the service. The introduction of the adhesive makes scarf-repaired composite laminate more sensitive to moisture environment than intact laminate, so moisture absorption properties of scarf-repaired laminates should be studied. There have been many researches performed on moisture absorption mechanism of bulk adhesives [6-9] and composite laminates $[10,11]$, and the investigation results show that the moisture environment can decrease mechanical properties of both bulk adhesives [12] and composite laminates $[13,14]$. Only a few investigations have been conducted on the moisture absorption properties of two-dimensional scarf joints and scarf-repaired laminates. Ahn et al. [15] and Ealdi [16] performed tensile tests of composite scarf joints in hygrothermal environment conditions and found that the hygrothermal environments reduce tensile strengths of the joints. Feng et al. [17] and Charalambides et al. [18] tested the tensile properties of bulk adhesives and composite 
scarf joints after moisture absorption. The results indicate that the negative effect of moisture absorption on the strengths of scarf joints is less than that of bulk adhesives, and the failure mode of the joints in the moisture environment has changed compared with the dry environment. A linear relation exists between the strength reduction of scarf joints and their moisture contents. Wu et al. [19] compared the damage tolerance of composite scarf joints and stepped-lap joints under tensile load in room temperature/dry $(\mathrm{RD})$ and elevated temperature/wet $(\mathrm{EW})$ conditions. The results show that the two joints possess similar damage tolerance with the consideration of the adhesive nonlinearity in RD and EW. Cheng et al. [14] investigated the compressive properties of scarf-repaired laminates in four hygrothermal environment conditions experimentally and numerically. They found that hygrothermal environments result in the reduction of structural mechanical properties due to hygrothermal stresses and material degradation, and the interfaces between the adhesive and laminates are easier to fail in the moisture environments.

In scarf repair practice, the over-ply is always used to cover the bondline on structure surfaces. Some researchers have studied the effect of the over-ply on mechanical properties of scarf-repaired laminates. Liu et al. [20] and Breitzman et al. [21] explored the effect of over-ply on tensile damage mechanism of scarf-repaired laminates and discussed the influence of over-ply number. The results show that the over-ply contributes to the increase of tensile strength of scarf-repaired laminates as the over-ply can release stress concentration in the plies close to it, and the tensile strengths hardly increase with more than 3 over-plies. Robson et al. [22] discussed the 
effect of over-ply stacking sequence on mechanical properties of scarf-repaired laminates and found that $0^{\circ}$ over-ply is preferred for longitudinal loading, and a pair of $\pm 45^{\circ}$ plies is nearly as effective as a single $0^{\circ}$ ply. Harman et al. [23] investigated the post-impact mechanical properties of scarf-repaired laminates with scarf-shape over-ply. The results show that the over-ply improves post-impact compressive strengths of scarf-repaired laminates, and the critical impact location for post-impact tensile strength of the laminates is within the scarf area of the over-ply.

For a scarf-repaired laminate, the moisture diffusion is easier along the adhesive than across the laminate as the moisture diffusivity constant and solubility of the adhesive is obviously larger. The over-ply covering the bondline prevents the adhesive exposing in the moisture environment directly, so it may decelerate moisture absorption of the adhesive and improve the mechanical properties of scarf-repaired laminates in moisture environment. However, current investigations on the over-ply focus on the effect on mechanical properties of scarf-repaired laminates in dry condition. Therefore, the effect of the over-ply on moisture absorption behavior of scarf-repaired composite laminate deserves to be studied.

In this paper, 3D finite element models of scarf-repaired laminates with and without over-ply were firstly established to simulate the moisture absorption behavior. Then, the models with and without over-plies were used to discuss the effects of over-ply type, configuration, direction and number. The results of this work can be as a reference for over-ply design of scarf-repaired laminates applied in moisture environments. 


\section{Numerical method}

\subsection{Finite element model}

Finite element model of scarf-repaired composite laminate with over-ply is built based on the model without over-ply which was used to conduct comparative studies on the effect of the over-ply. Finite element model of scarf-repaired composite laminate without over-ply was firstly established by ABAQUS software. The scarf-repaired laminate consists of the adherends (i.e. parent and patch) and adhesive as shown in Fig. 1. The unit of the configuration in Fig. 1 is millimeter, which the following content is accordance with. Both of the adherends were made of CCF300/5228A (carbon fiber/epoxy) with the stacking sequence of $\left[45 / 0_{2} /-45 / 90 / 45 / 0_{2} /-45 / 0\right]_{s}$. The nominal thickness of each ply is $0.125 \mathrm{~mm}$. A layer of adhesive film SY-14M with nominal thickness of $0.13 \mathrm{~mm}$ was used to bond the parent and patch.

There were 20 layer elements in the thickness direction of the adherends to simulate each composite ply, while the adhesive was one layer in its thickness direction. 1/4 model was adopted to reduce the amount of calculation. The meshing of the model is shown in Fig. 2. The element type of all the models is DC3D8. 


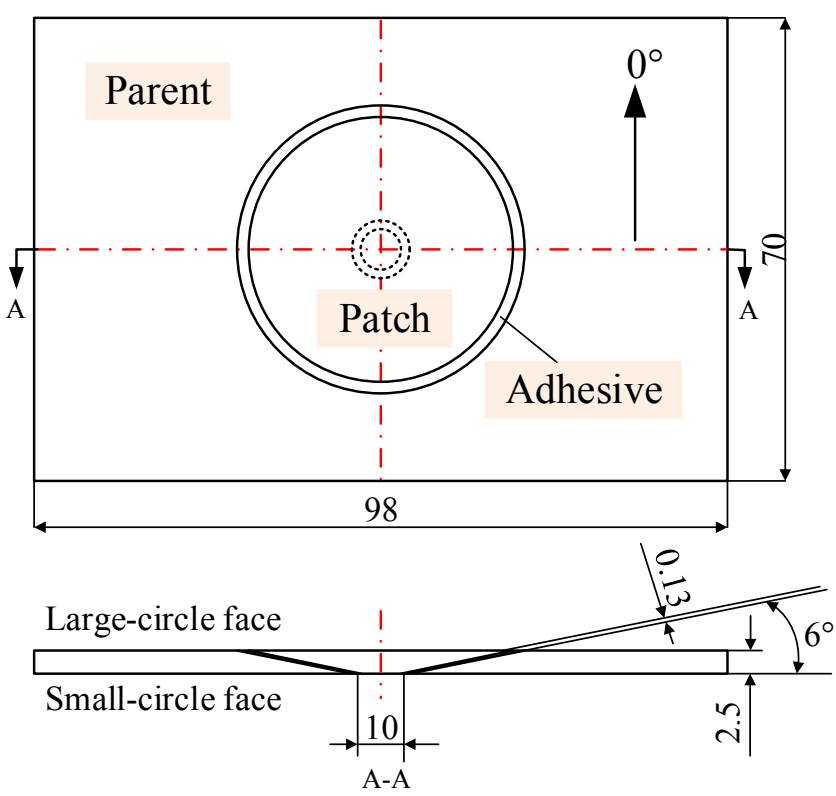

Fig. 1 Scarf-repaired laminate configuration

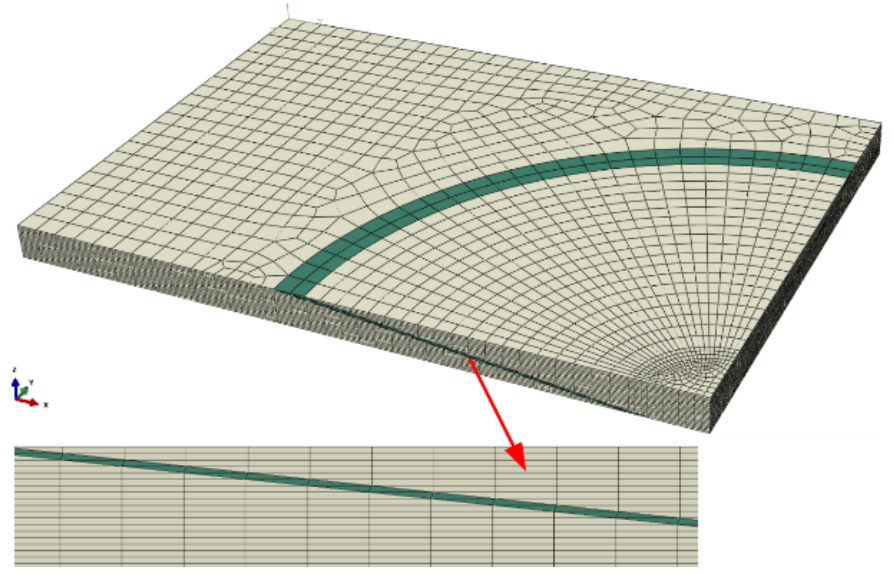

Fig. 2 Finite element model of scarf-repaired laminate without over-ply

\subsection{Moisture absorption model}

Moisture diffusion was analyzed by using "Mass Diffusion/Transient" module based on Fick's law [14] in ABAQUS. Based on this law, if the initial moisture content was zero, the content can be approximated as following,

$$
M(t)=M_{\infty}\left\{1-\exp \left[-7.3\left(\frac{D t}{H}\right)^{0.75}\right]\right\}
$$




$$
D=\pi H^{2}\left(\frac{K}{4 M_{\infty}}\right)^{2}
$$

In which subscript $\infty$ denotes the moisture absorption equilibrium condition, $D$ is moisture diffusivity constant, $t$ is time, $H$ is specimen thickness and $K$ is the initial slope of moisture content-time curves.

At the initial stage ( $t$ is very small), Eq. (2) can be simplified as,

$$
M(t)=4 M_{\infty} \sqrt{\frac{D t}{\pi H^{2}}}
$$

This indicates that moisture content is directly proportional to square root of time at the initial stage.

The mass diffusion element has only one degree of freedom, namely the normalized concentration $\phi$, which is defined as follows:

$$
\phi=c / s
$$

Where $c$ is the mass concentration of the diffusing material, and $s$ is the solubility of the diffusing material in the reference material. The mass diffusion process follows the law of mass conservation, as follows:

$$
\int_{V} \frac{d c}{d t} d V+\int_{S} \mathbf{n} \cdot \mathbf{J} d S=0
$$

Where $V$ is the volume, $S$ is the surface area, $\mathbf{n}$ is the normal vector of $S$, and $\mathbf{J}$ is the moisture diffusion flux.

Moisture diffusivity constant $(D)$ and solubility $(s)$ of the water in the composite CCF300/5228A and adhesive SY14M should be given in the moisture diffusion modeling. For adhesive SY14M, $D=0.0226 \mathrm{~mm}^{2} / \mathrm{h}$ and $s=0.0635$ [12]. For composite CCF300/5228A, $s=0.0161$, and the longitudinal, transverse and through-thickness 
moisture diffusivity constants $\left(D_{11}, D_{22}, D_{33}\right)$ are $0.012 \mathrm{~mm}^{2} / \mathrm{h}, 3.38 \times 10^{-3} \mathrm{~mm}^{2} / \mathrm{h}$ and $3.38 \times 10^{-3} \mathrm{~mm}^{2} / \mathrm{h}$, respectively [24]. In addition, the boundary condition is that the moisture saturation situation ( $\phi$ ) on the structural outer surfaces is 1 .

Based on the FEM without over-ply, the models with over-ply were developed by adding the adhesive layer on the local laminate surface of repaired region and the over-ply on it. In order to distinguish from the adhesive in scarf interface, the adhesive under the over-ply is named as upper adhesive here. The materials of the over-ply and upper adhesive are the same as the adherends and adhesive respectively in this work, although they can be other materials. The method and principle of finite element analysis and moisture absorption modeling on scarf-repaired laminate with over-ply are the same as those without over-ply. The numerical results without over-ply would be compared with experimental data to validate this numerical modeling method.

\section{Model verification}

\subsection{Moisture absorption test}

The configuration of scarf-repaired specimens (labeled as EXP1 EXP5) has shown in Fig. 1 with manufacturing processes consistent with Ref. [25]. Images of the specimens are shown in Fig. 3. Moisture absorption experiment was performed based on ASTM Standard D5229 [26]. Specimens were immersed in a deionized water tank with the temperature of $95^{\circ} \mathrm{C}$. Specimen weight was regularly measured by an analytical balance with the accuracy of $1 \mathrm{mg}$. The specimens were taken out of the water and cleaned with an absorbent cloth, and then weighed in 5min. Moisture 
absorption equilibrium achieved when the following equation was met.

$$
\left|M_{i}-M_{i-1}\right|<0.02 \%
$$

Where $M=\left(W-W_{\mathrm{b}}\right) / W_{\mathrm{b}} . M$ is the moisture content, $W_{\mathrm{b}}$ is initial oven-dry specimen mass, and $W$ is current specimen mass. The subscript $i$ and $i-1$ denote the ordinal number of current time and last time respectively.
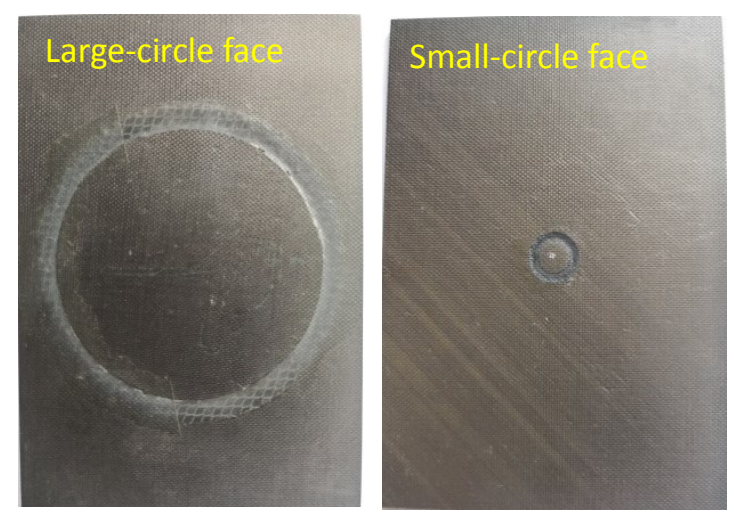

Fig. 3 Images of the specimens

\subsection{Comparison of experimental and numerical results}

Experimental and numerical moisture absorption curves of scarf-repaired laminates without over-ply are shown in Fig. 4, in which FE denotes numerical results. It can be found the finite element results are in good agreement with experimental results, thus this numerical modeling method is efficient.

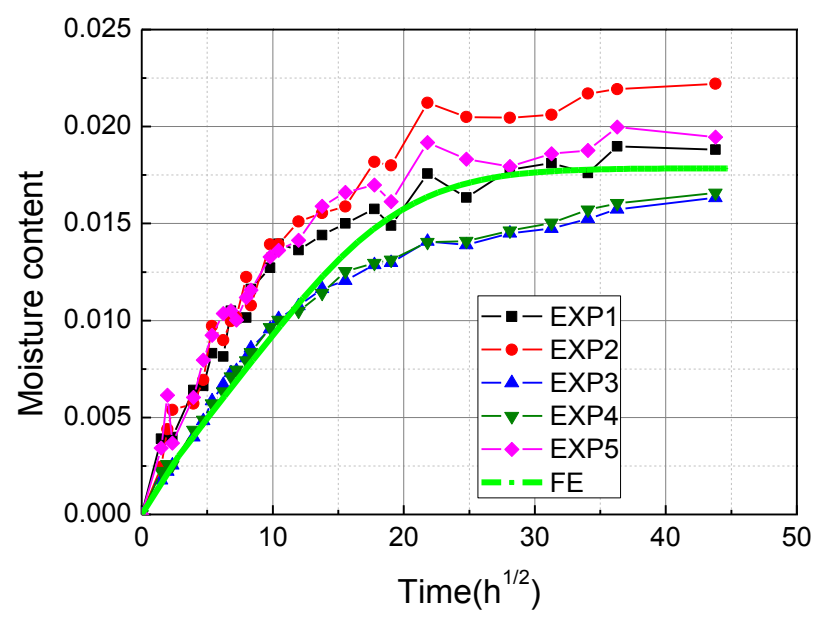


Fig. 4 Experimental and numerical moisture absorption content versus the square root of time curves of scarf-repaired laminates without over-ply

\section{Results and Discussion}

The numerical models of scarf-repaired laminates with over-plies were established using that numerical modeling method validated above. These models involve different types, configurations, directions and numbers of the over-plies to deeply investigate the effect of over-ply on moisture absorption behavior of scarf-repaired composite laminates.

\subsection{Effect of over-ply type}

Over-ply type refers to the bonding form between the over-ply and scarf-repaired laminate. Three over-ply types were studied as shown in Fig. 5, in which Type 1 denotes the whole single side bonded with the upper adhesive and Type 2 denotes partial single side bonded, and Type 3 denotes double sides bonded partially.

In this work, one over-ply with direction of $0^{\circ}$ was used and the upper adhesive thickness was $0.125 \mathrm{~mm}$ (the same as the composite ply thickness) to make the structure flat. The ply under the over-ply (named as intermediate ply) in Type 2 and Type 3 possessed the same direction of $0^{\circ}$. All the over-ply lap length is $5 \mathrm{~mm}$, the effect of which would be discussed in the next section. 


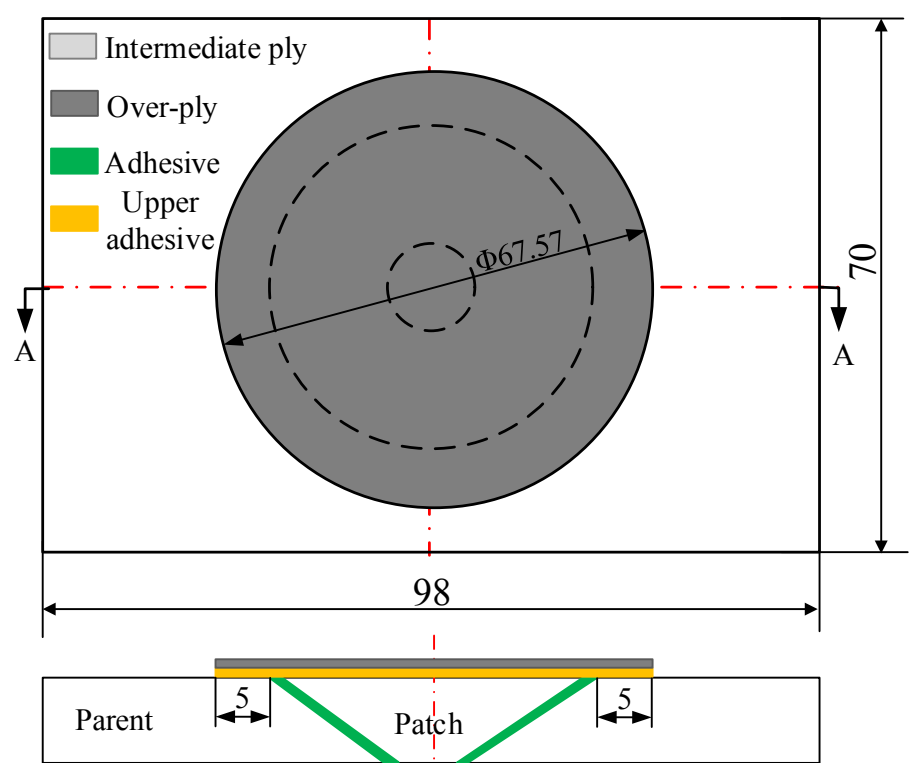

(a) Type 1

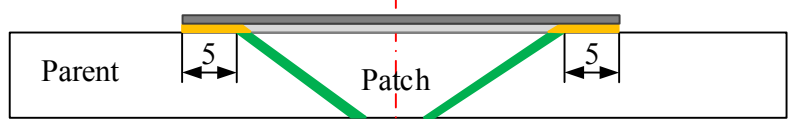

(b) Type 2

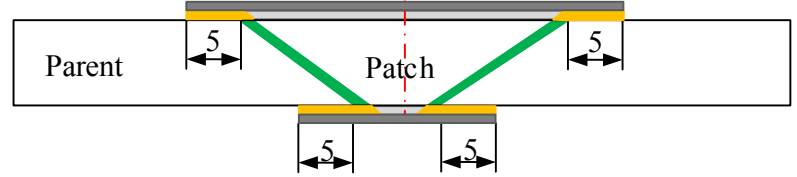

(c) Type 3

Section A-A

Fig. 5 Schematic diagrams of moisture absorption models with different over-ply

$$
\text { types }
$$

Moisture absorption curves of scarf-repaired laminates with different over-ply types are shown in Fig. 6. Fig. 6(a) shows that the introduction of the over-ply can efficiently decelerate moisture absorption of the adhesive and delay the time of moisture absorption equilibrium. In general, the effect of Type 3 is greater than that of Type 1 and Type 2 which are similar. But the curves of all three over-ply types basically become the same in later stage, which means double surfaces covered with over-plies can only impede the adhesive absorbing moisture in the early stage, but not in the later stage. Fig. 6(b) shows that over-ply type has little effect on moisture 
absorption performances of the adherends. And the moisture absorption rates and equilibrium contents of the whole repaired structures increase due to the introduction of the over-ply and upper adhesive, especially for Type 1, as shown in Fig. 6(c).

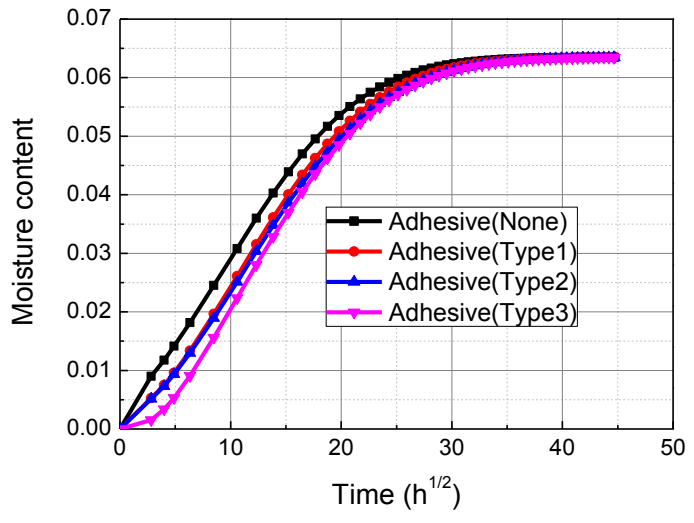

(a) Adhesives

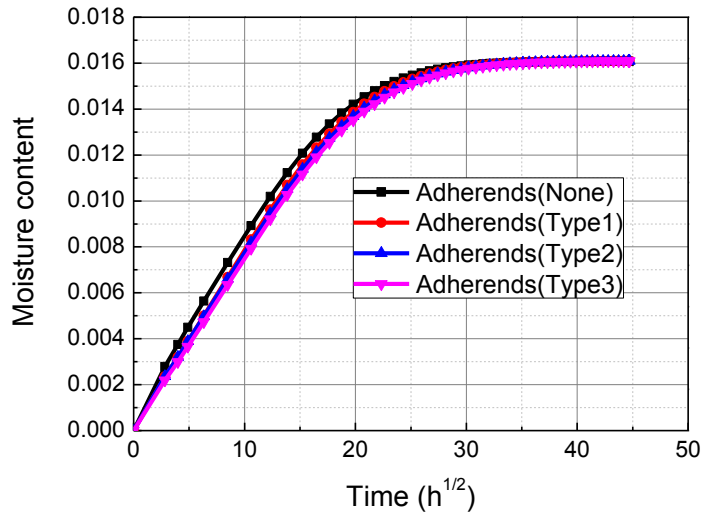

(b) Adherends

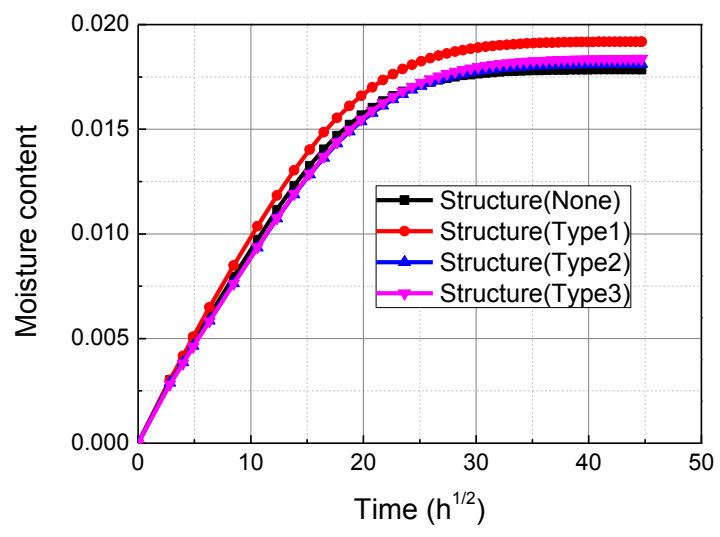

(c) Structures

Fig. 6 Moisture absorption curves of scarf-repaired laminates with different over-ply types ("None” in legends denotes without over-ply)

Type 2 does not increase structural moisture content compared with Type 1 . Not only that, but also it is more easily operated for low accessible regions at the small-circle face. Thus Type 2 is preferred and only this type would be studied in the following investigation. 
Moisture absorption curves of the adhesive close to its two end surfaces in the scarf-repaired laminate using Type 2 are shown in Fig. 7. It can be found that point B (close to the free surface) instantly reaches the moisture absorption equilibrium, while point A (close to the covered surface) achieves the equilibrium 900h later. That means the over-ply has a great negative effect on moisture absorption rate of the adhesive close to it.

As damages of scarf-repaired laminate suffered axial loads always initiate around the bondline on the large-circle face, and moisture environment can decrease mechanical properties of the adhesive [27], the over-ply can increase the damage initiation strength of scarf-repaired laminates in moisture conditions. If the moisture diffusivity can be resisted by the over-ply, it will be a great benefit to scarf-repaired laminates. Therefore, moisture absorption properties of the over-ply and upper adhesive should be paid special attention with their material selection.

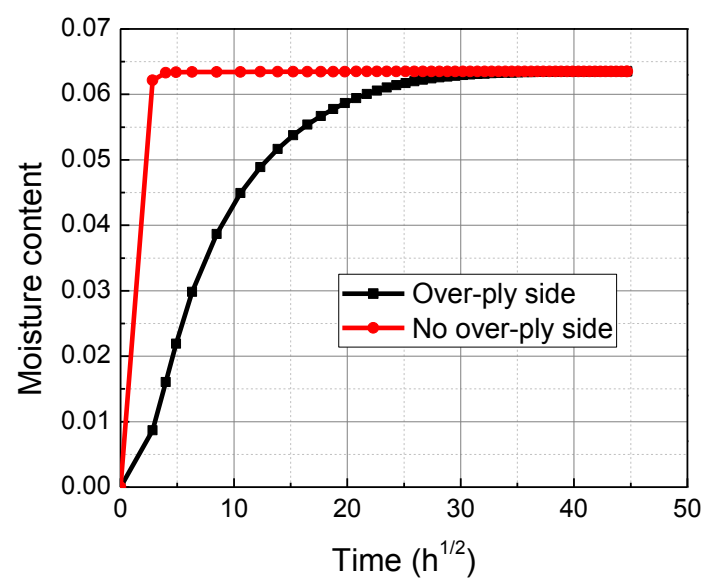

Fig. 7 Moisture absorption curves of the adhesive close to its two end surfaces (Point A and point B are shown in Fig. 7

Moisture mass flow (MFL) vectors of the scarf-repaired laminate using Type 2 at 
112h are shown in Fig. 8. From Fig. 8 (a) and (b), it can be found that the moisture is mainly transferred along the thickness direction for composite laminates (over-ply and adherends). From Fig. 8 (c) and (d), moisture transfer directions of the upper adhesive and adhesive can be divided into two paths, namely along the bondline and structural thickness. The MFL values of the upper adhesive and adhesive are obviously greater than those of the over-ply and adherends, for moisture diffusivity constant and solubility of the adhesive are obviously larger than those of the composite laminates.

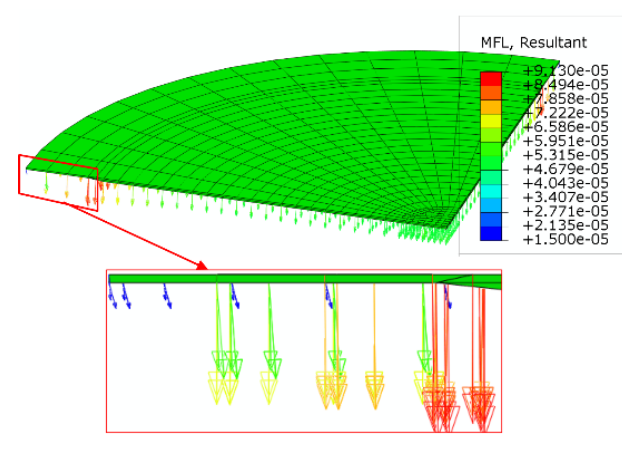

(a) Over-ply

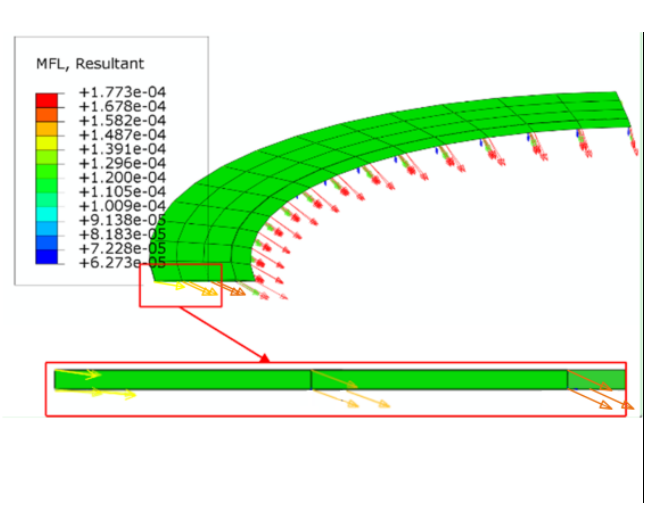

(c) Upper adhesive

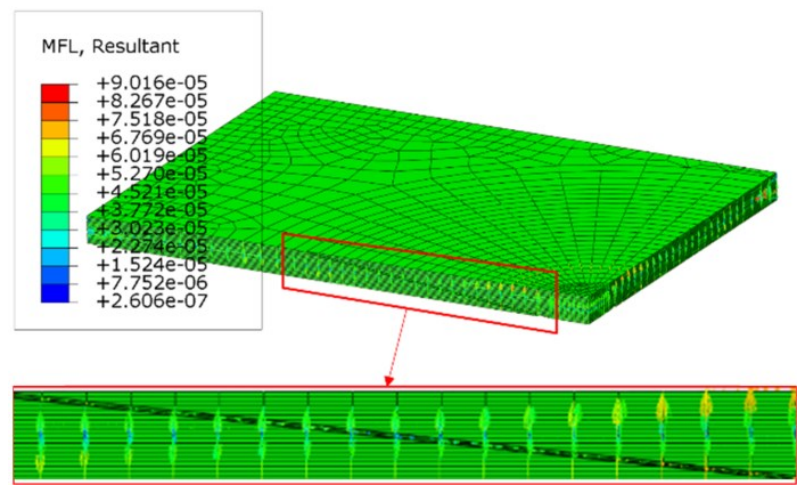

(b) Adherends

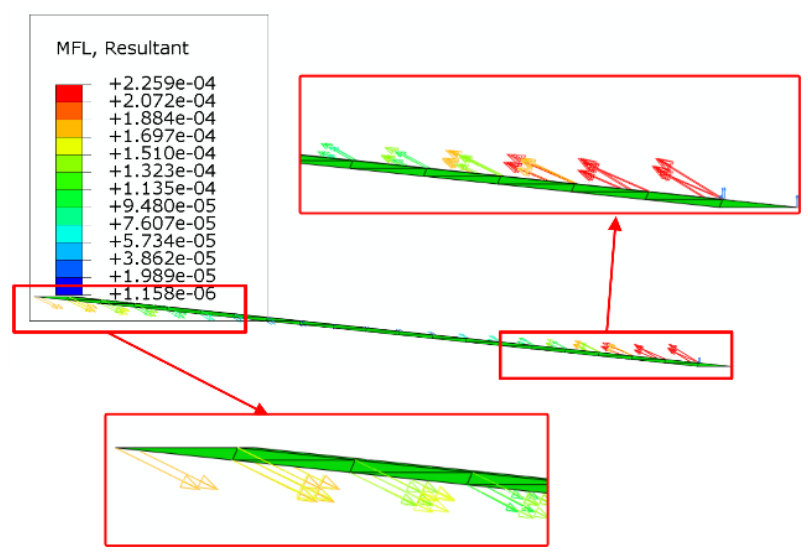

(d) Adhesive

Fig. 8 MFL vectors of the scarf-repaired laminate using Type 2 at $112 \mathrm{~h}$

In order to further investigate the variation of two-path distributions in the adhesive during moisture absorption, its MFL vectors for Type 2 at $112 \mathrm{~h}$ and $2000 \mathrm{~h}$ 
are shown in Fig. 9, in which $\theta_{\mathrm{A}}$ and $\theta_{\mathrm{B}}$ are the angles between MFL vectors and radial bondline surface at point $\mathrm{A}$ and point $\mathrm{B}$. The less $\theta$ value means greater MFL component along the bondline. It can be found that the MFL along the bondline increases with time increasing due to the larger moisture concentration and greater gradient around point $\mathrm{A}$ and point $\mathrm{B}$ in later stage. The MFL component along the bondline close to the covered surface is less than that close to the free surface at $112 \mathrm{~h}$, while The MFL component close to the covered surface is greater than that close to the free surface at $2000 \mathrm{~h}$. This is because the moisture concentration at point A slowly increases due to over-ply in early stage, which causes less moisture gradient along the bondline close to the covered surface than that close to the free surface. In later stage, the moisture concentration of point A and point B is similar. The adhesive close to the covered surface possesses greater moisture concentration than that close to the free surface, so the moisture gradient close to the free surface is less than that close to the covered surface.

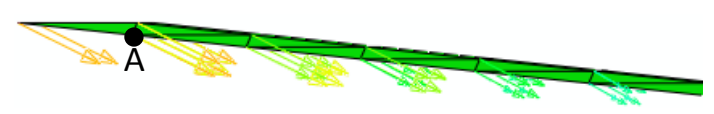

(a) over-ply side at $112 \mathrm{~h}\left(\theta_{\mathrm{A}}=19.5^{\circ}\right)$

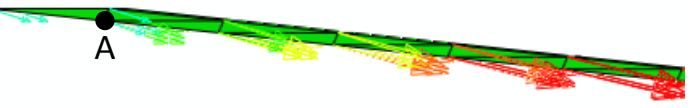

(c) over-ply side at $2000 \mathrm{~h}\left(\theta_{\mathrm{A}}=9.1^{\circ}\right)$

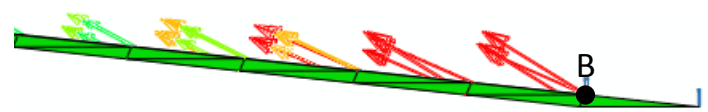

(b) no over-ply side at $112 \mathrm{~h}\left(\theta_{\mathrm{B}}=17.5^{\circ}\right)$

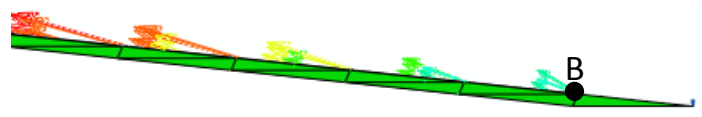

(d) no over-ply side at $2000 \mathrm{~h}\left(\theta_{\mathrm{B}}=13.8^{\circ}\right)$

Fig. 9 MFL vectors of the adhesive in the scarf-repaired laminate using Type 2 at $112 \mathrm{~h}$ and 2000h (the colors of arrows denote the value of MFL vectors like in Fig. 


\subsection{Effect of over-ply configuration}

Over-ply configuration refers to the over-ply lap length or shape here. Three lap lengths and two shapes with Type 2 were studied as shown in Fig. 10. The models were established based on that one in section 4.1 with the configurations of the over-ply and upper adhesive changed. The upper adhesive region is the residual part of the over-ply projection except intermediate ply.

The moisture absorption curves of their adhesives, adherends and structures are shown in Fig. 11. The results show the over-ply configuration hardly affects the moisture absorption behavior of scarf-repaired laminates.

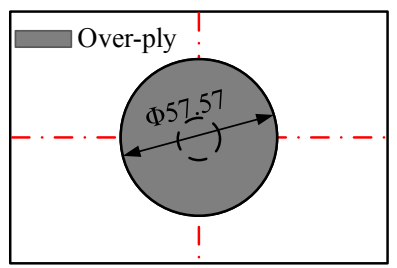

(a) Lap length $=0$

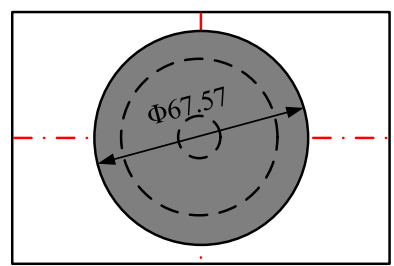

(c) Lap length=5

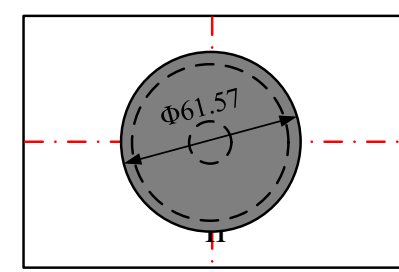

(b) Lap length=2

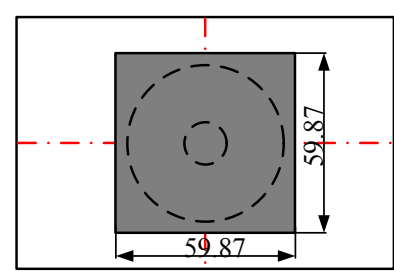

(d) Square

Fig. 10 Schematic diagram of moisture absorption model with different over-ply configurations 


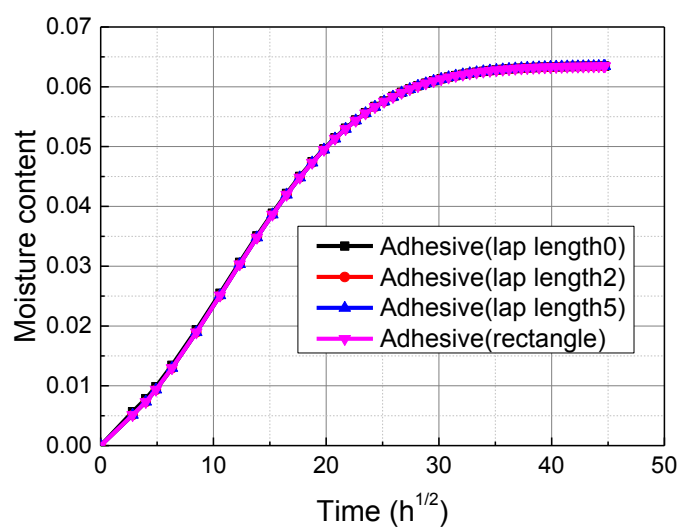

(a) Adhesives

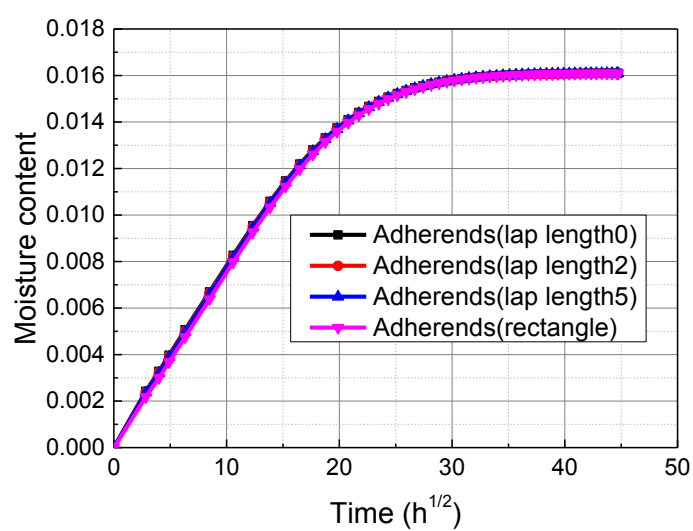

(b) Adherends (patches and parents)

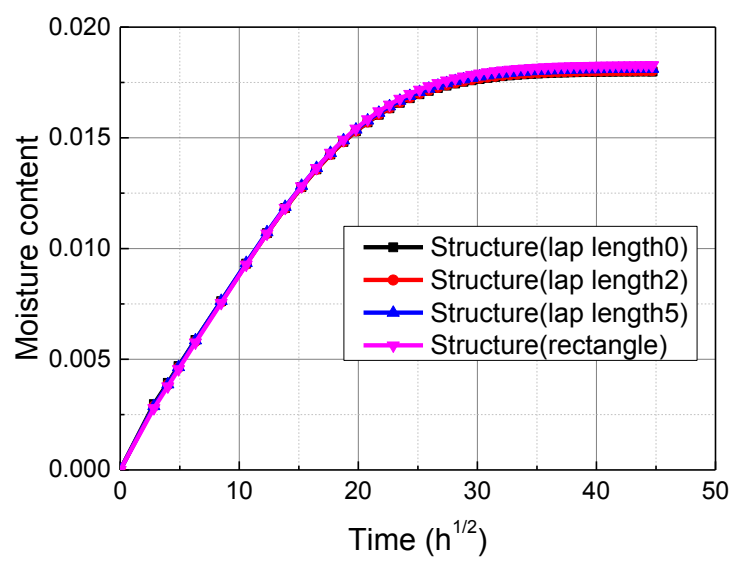

(c) Structures

Fig. 11 Moisture absorption curves of scarf-repaired laminates with different

$$
\text { over-ply configurations }
$$

In order to further study the local effect of over-ply configuration, $\theta$ and $M F L$ values at point A (see Fig. 8) are listed in Table 1, and moisture absorption curves of local area of the adhesive close to covered surface (three-layer element thickness) are shown in Fig. 12. It can be found that moisture absorption rate of the adhesive without over-ply (lap length $=0$ ) is greater than that with over-ply (lap length $\neq 0$ ). This effect is obvious as the horizontal ordinate is the root of time, which means that the over-ply contributes to the increase of fatigue life of repaired laminates. And over-ply 
configuration has little effect on moisture absorption curve and path distribution of the adhesive. Therefore, lap length should be greater than zero, but its value is not important.

Table $1 \theta$ and $M F L$ values at point A with different over-ply configurations

\begin{tabular}{|c|c|c|}
\hline Over-ply configuration & $\theta_{\mathrm{A}}$ at $112 \mathrm{~h} /{ }^{\circ}$ & $M F L$ values at Point A \\
\hline Circle (Lap length=0) & 15.9 & $2.17 \mathrm{e}-4$ \\
\hline Circle (Lap length=2) & 19.6 & $1.65 \mathrm{e}-4$ \\
\hline Circle (Lap length=5) & 19.5 & $1.67 \mathrm{e}-4$ \\
\hline Square $(59.86 \times 59.86 \mathrm{~mm})$ & 18.8 (Lap length $1=1.21 \mathrm{~mm})$ & $1.726 \mathrm{e}-4$ \\
& 20.2 (Lap length $2=13.6 \mathrm{~mm})$ & $1.68 \mathrm{e}-4$ \\
\hline
\end{tabular}

Note: Lap length 1 is the distance between square edge and patch large circle, while Lap length 2 is the distance between square angle point and patch large circle.

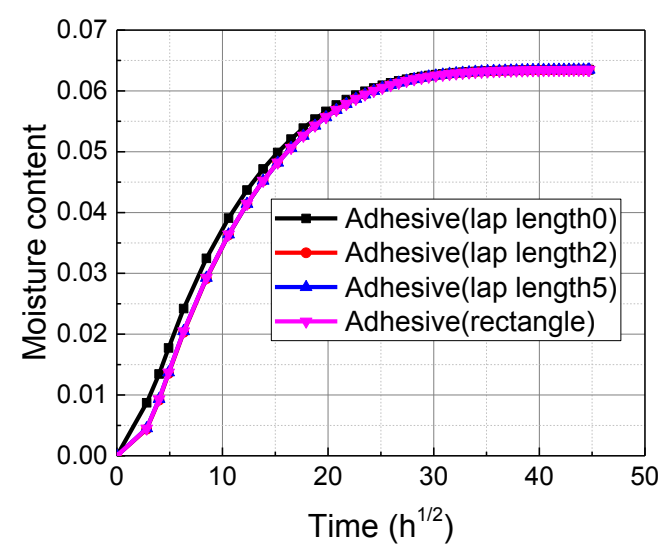

Fig. 12 Moisture absorption curves of local area of the adhesive close to covered surface in scarf-repaired laminates with different over-ply configurations

\subsection{Effect of over-ply direction}

The model was the same as that one in section 4.1 , but the directions of the over-ply and intermediate ply were variable. Over-ply direction refers to the direction combination of the two plies.

Three types of over-ply directions were studied here as shown in Table 2, in which "In" and "out" denote the intermediate ply and over-ply respectively, and the 
following numbers are the ply directions. The corresponding moisture absorption curves are shown in Fig. 13. It can be found that the direction has no effect on moisture absorption behavior of the adhesive, adherends and structures, either on that of local adhesive, when the over-ply and intermediate ply are unidirectional tapes. But woven ply can extremely decelerate the moisture absorption.

$\theta_{\mathrm{A}}$ with unidirectional and woven over-plies were compared in Table 3 . The value of $\theta_{\mathrm{A}}$ with woven over-ply is obviously greater than that with unidirectional over-ply in early stage and tends to be the same in later stage. That means that woven over-ply can make the MFL component along the bondline relatively smaller and obviously affect moisture behavior of the adhesive in early stage. One woven over-ply is more efficient than one unidirectional over-ply to protect scarf-repaired laminate from moisture absorption, but the woven ply is a little thicker.

Table 2 Three types of over-ply directions

\begin{tabular}{|c|c|c|c|}
\hline Label & $\begin{array}{c}\text { All over-ply } \\
\text { thickness/mm }\end{array}$ & $\begin{array}{c}\text { Inside over-ply } \\
\text { direction/ }\end{array}$ & $\begin{array}{c}\text { Outside over-ply } \\
\text { direction } /{ }^{\circ}\end{array}$ \\
\hline In0_out0 & 0.250 & 0 & 0 \\
\hline In-45_out45 & 0.250 & -45 & 45 \\
\hline In0_out(0/90) & 0.437 & 0 & $(0 / 90)$ \\
\hline
\end{tabular}

Note: for unidirectional ply, $\mathrm{s}=0.0161 . \mathrm{D}_{11}, \mathrm{D}_{22}$ and $\mathrm{D}_{33}$ are $0.012 \mathrm{~mm}^{2} / \mathrm{h}, 3.38 \mathrm{e}-3 \mathrm{~mm}^{2} / \mathrm{h}$ and $3.38 \mathrm{e}-3 \mathrm{~mm}^{2} / \mathrm{h}$ respectively. For woven ply, s=0.0185. $\mathrm{D}_{11}, \mathrm{D}_{22}$ and $\mathrm{D}_{33}$ are $1.84 \times 10^{-4} \mathrm{~mm}^{2} / \mathrm{h}$, $1.84 \times 10^{-4} \mathrm{~mm}^{2} / \mathrm{h}$ and $1.84 \times 10^{-3} \mathrm{~mm}^{2} / \mathrm{h}$. The thickness of woven ply is $0.312 \mathrm{~mm}$.
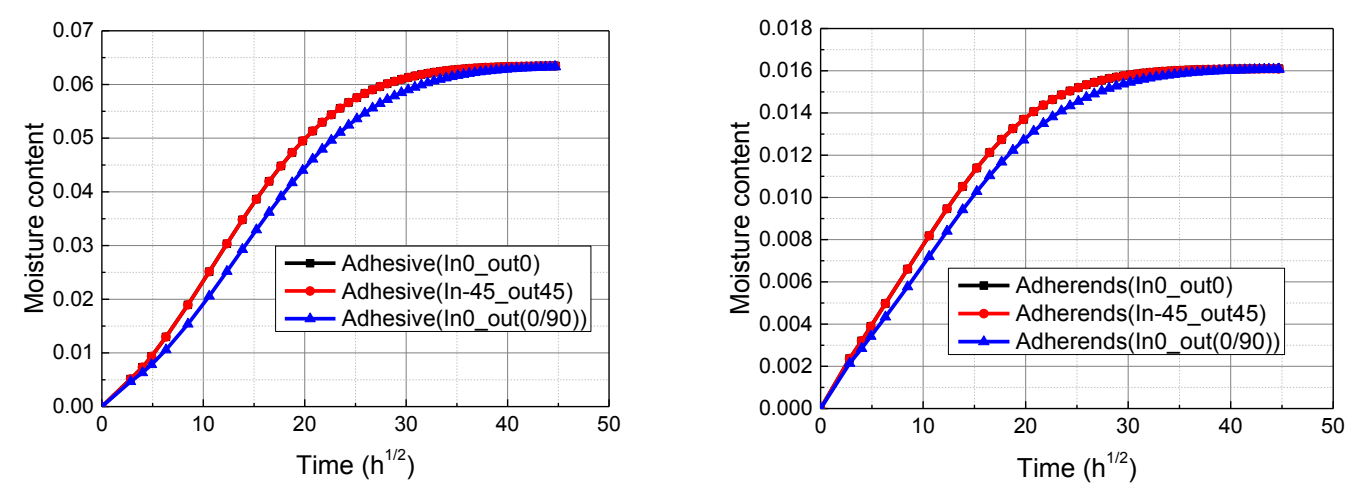

(a) Adhesives
(b) Adherends (patches and parents)

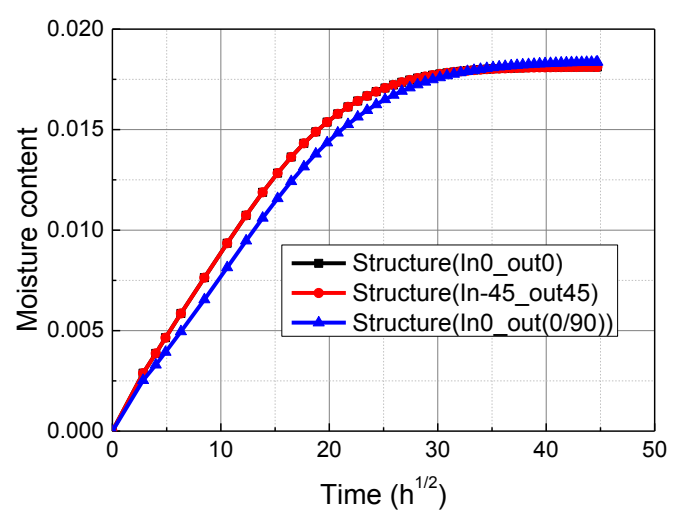

(c) Structures

Fig. 13 Moisture absorption curves of scarf-repaired laminates with different

over-ply directions

Table $3 \theta_{\mathrm{A}}$ with unidirectional and woven over-plies

\begin{tabular}{|c|c|c|}
\hline Over-ply direction & $\theta_{\mathrm{A}}$ at $112 \mathrm{~h}$ & $\theta_{\mathrm{A}}$ at $2000 \mathrm{~h}$ \\
\hline Unidirectional (In0_out0) & $19.5^{\circ}$ & $9.1^{\circ}$ \\
\hline Woven (In0_out(0/90)) & $24.3^{\circ}$ & $9.6^{\circ}$ \\
\hline
\end{tabular}

\subsection{Effect of over-ply number}

Based on section 4.3 , three ply numbers of $0^{\circ}$ unidirectional over-plies were studied here and they were compared with one woven over-ply case, as listed in Table 4.

Moisture absorption curves of scarf-repaired laminates with different over-ply numbers are shown in Fig. 14. It can be found that more over-ply number contribute to less moisture absorption rate. Three unidirectional over-plies have larger thickness than one woven over-ply, but their effect to protect structures from moisture absorption is worse than woven case. Therefore, woven over-ply is more effective than unidirectional over-ply to protect scarf-repaired laminates from moisture absorption. 
Table 4 Over-ply number cases

\begin{tabular}{|c|c|c|c|}
\hline Label & $\begin{array}{c}\text { Thickness of } \\
\text { covered plies/mm }\end{array}$ & $\begin{array}{c}\text { Intermediate ply } \\
\text { direction } /{ }^{\circ}\end{array}$ & ${\text { Over-ply direction } /{ }^{\circ}}^{\circ}$ \\
\hline Num2_uni & 0.250 & 0 & 0 \\
\hline Num3_uni & 0.375 & 0 & $0 / 0$ \\
\hline Num4_uni & 0.500 & 0 & $(0 / 90)$ \\
\hline Num2_woven & 0.437 & 0 & \\
\hline
\end{tabular}

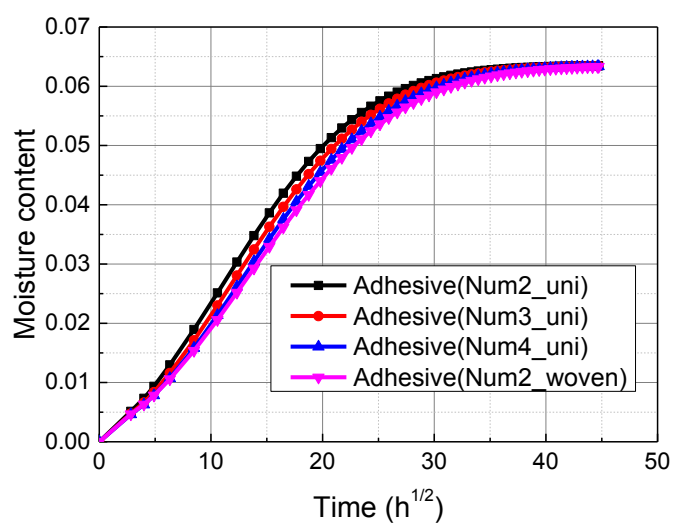

(a) Adhesives

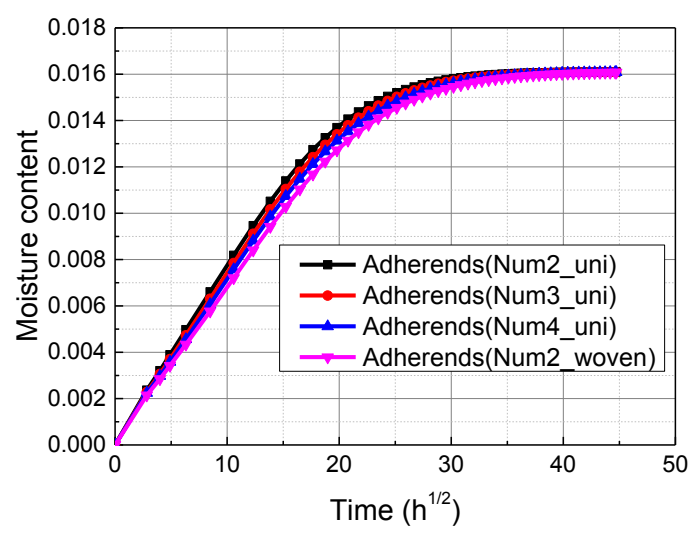

(b) Adherends

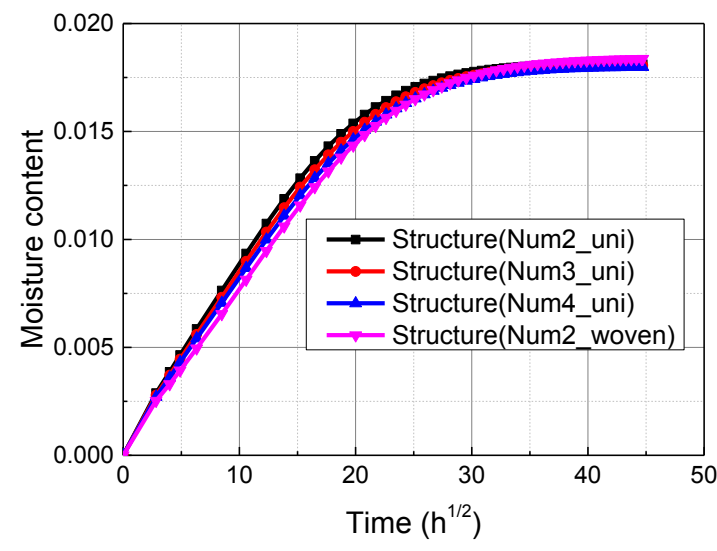

(c) Structures

Fig. 14 Moisture absorption curves of scarf-repaired laminates with different over-ply numbers

\section{Conclusions}

In this paper, moisture absorption models with and without over-plies were 
established and verified by experimental results. Based on the models, the effects of over-ply type, configuration, direction and number were discussed. The following conclusions have been obtained:

(1) Moisture transfer directions of the adhesive can be divided into two paths: one is along the bondline and the other is along the structural thickness. The component along the bondline close to the covered surface is less than that at close to the free surface in early stage, but the situation becomes opposite in later stage.

(2) The introduction of the over-ply can efficiently decelerate moisture absorption of the adhesive and delay the time of its moisture absorption equilibrium. Over-ply type has little effect on moisture absorption performances of adherends. And the moisture absorption rates and equilibrium contents of the whole repaired structures increase due to the introduction of the over-ply and upper adhesive.

(3) In over-ply design with scarf-repaired laminates, Type 2 is better than Type 1 and Type 3 for less structural moisture content and more easily operated for low accessible regions respectively. Moisture absorption properties of the over-ply and upper adhesive should be highlighted in material selection for they have great effect on moisture absorption rate of the adhesive close to the covered surface. Over-ply lap length configuration and direction are not very important parameters, but the bondline on large-circle face should be covered by the over-ply. Woven over-ply is more effective to protect scarf-repaired laminates from moisture absorption than unidirectional over-ply.

\section{Data availability statement}

The raw/processed data required to reproduce these findings cannot be shared at 
this time as the data also forms part of an ongoing study.

\section{References}

[1] Cheng XQ, Zhang J, Bao JW, Zeng BY, Cheng YJ, Hua RW. Low-velocity impact performance and effect factor analysis of scarf-repaired composite laminates. International Journal of Impact Engineering 2017; 111: 85-93.

[2] Cheng XQ, Zhang J, Zhang JK, Liu P, Cheng YJ, Xu YH. Numerical analysis on tensile properties of composite hybrid bonded/bolted joints with flanging. Steel and Composite Structures 2018; 26(3): 265-272.

[3] Khashaba UA, Aljinaidi AA, Hamed MA. Fatigue and reliability analysis of nano-modified scarf adhesive joints in carbon fiber composites. Composites Part B: Engineering 2017; 120: 103-117.

[4] Campilho RDSG, De Moura M, Pinto AMG, Morais JJL, Domingues JJMS. Modelling the tensile fracture behaviour of CFRP scarf repairs. Composites Part B: Engineering 2009; 40(2): 149-157.

[5] Cheng XQ, Du XY, Zhang J, Zhang JK, Guo X, Bao JW. Effects of stacking sequence and rotation angle of patch on low velocity impact performance of scarf repaired laminates. Composites Part B: Engineering 2018; 133: 78-85.

[6] Bao LR, Yee AF. Effect of temperature on moisture absorption in a bismaleimide resin and its carbon fiber composites. Polymer 2002; 43(14): 3987-3997.

[7] Bao LR, Yee AF. Moisture diffusion and hygrothermal aging in bismaleimide matrix carbon fiber composites-part I: uni-weave composites. Composites Science \& Technology 2002; 62(16): 2099-2110.

[8] Bao LR, Yee AF. Moisture diffusion and hygrothermal aging in bismaleimide matrix carbon fiber composites: part II-woven and hybrid composites. Composites Science \& Technology 2002; 62(16): 2111-2119.

[9] Xiao GZ, Shanahan MER. Swelling of DGEBA/DDA epoxy resin during hygrothermal ageing. Polymer 1998; 39(14): 3253-3260.

[10] Xu J, Kolstein H, Bijlaard FS. Moisture diffusion in glass-fiber-reinforced polymer composite bridge under hot/wet environment. Composites Part B: 
Engineering 2013; 45(1): 407-416.

[11]Zafar A, Bertocco F, Schjodt-Thomsen J, Rauhe JC. Investigation of the long term effects of moisture on carbon fibre and epoxy matrix composites. Composites Science and Technology 2012; 72: 656-666.

[12]Liu SF, Cheng XQ, Zhang Q, Zhang, Bao JW, Guo X. An investigation of hygrothermal effects on adhesive materials and double lap shear joints of CFRP composite laminates. Composite Part B 2016; 91:431-440.

[13]La Saponara V. Environmental and chemical degradation of carbon/epoxy and structural adhesive for aerospace applications: Fickian and anomalous diffusion, Arrhenius kinetics. Composite Structures 2011; 93: 2180-95.

[14]Cheng XQ, Liu SF, Zhang JK, Guo X, Bao JW. Hygrothermal effects on mechanical behavior of scarf repaired carbon-epoxy laminates subject to axial compression loads: Experiment and numerical simulation. Polymer Composites 2018, 39(3): 904-914.

[15]Ahn SH, Springer GS. Repair of composite laminates-I: test results. Journal of Composite Materials 1998; 32(11): 1036-1074.

[16]Elaldi F, Elaldi P. Processing and Environmental Effects on Composite Repairs. Materials and Manufacturing Processes 2012; 27: 255-259.

[17]Feng W, Xu F, Xie W, Zang YY, Zhang XY. Hygrothermal aging effects on the mechanical behavior of scarf-repaired composite laminates. The Journal of Adhesion 2019; 1-25.

[18]Charalambides MN, Hardouin R, Kinloch AJ, Matthews FL. Adhesively-bonded repairs to fiber-composite materials: Experimental. Composite Part A: Applied Science and Manufacturing 1998; 29(11): 1371-81.

[19] Wu C, Chen C, He L, Yan WY. Comparison on damage tolerance of scarf and stepped-lap bonded composite joints under quasi-static loading. Composites Part B: Engineering 2018; 155: 19-30.

[20]Liu J, Liu P, Qiu TW, Qiao LP, Liu S, Yang NH. Tensile performance of composite laminates after scarf repair. Forum of the third civil aircraft advanced manufacturing technology and equipment, 2011 (in Chinese). 
[21]Breitzman TD, Iarve EV, Cook BM, Schoeppner GA, Lipton RP. Optimization of a composite scarf repair patch under tensile loading. Composites Part A: Applied Science and Manufacturing 2009;40:1921-1930.

[22]Robson J, Matthews F, Kinloch A. The strength of composite repair patches: a laminate analysis approach. Journal of reinforced plastics and composites 1992; 11:729-742.

[23]Harman $A B$, Rider $A N$. Impact damage tolerance of composite repairs to highly-loaded, high temperature composite structures. Composites Part A: Applied Science and Manufacturing 2011;42:1321-1334.

[24] Shen CH, Springer GS. Moisture absorption and desorption of composite materials. Journal of composite materials 1976; 10(1): 2-20.

[25]Zhang J, Cheng XQ, Zhang JK, Guo X, Huang WJ, Effect of curing condition on bonding quality of scarf-repaired composite laminates 2019; https://doi.org/10.1016/j.cja.2019.08.016.

[26]ASTM Standard D5229/D5229M, Standard Test Method for Moisture Absorption Properties and Equilibrium Conditioning of Polymer Matrix Composite Materials. West Conshohocken, PA: ASTM International; 2014.

[27]Zhang J , Cheng X, Guo X, et al. Effect of environment conditions on adhesive properties and material selection in composite bonded joints[J]. International Journal of Adhesion and Adhesives, 2020;96:1-7. 